\title{
The Influence of First Generation Fertility and Economic Status on Second Generation Fertility*
}

\author{
Arland Thornton \\ The University of Michigan
}

This paper examines the impact of parental economic status and family size on the actual and expected fertility of adult children using longitudinal data from two generations of families participating in the Panel Study of Income Dynamics. There was a modest positive relationship between first generation family size and second generation fertility. More importantly, the ideal family size of the parental family was more closely related to fertility behavior and plans in the second generation than was actual parental family size. In addition, the data revealed the hypothesized negative correlation between parental financial status and second generation fertility behavior and plans. Several mechanisms which could produce the correlation between parental characteristics and the fertility of their children are explored.

The influence of the parental home in shaping the behavior of children is a well-established fact in social science. The purpose of this paper is to investigate the relationships between behavior and preferences of first generation parents and fertility in the second generation. Two specific dimensions of the parental family are examined. The first factor is the economic status and standard of living enjoyed in the parental home. The second dimension is first generation fertility: both actual and ideal family size. The impact of both of these first generation characteristics on second generation fertility are examined

*The analysis reported in this paper was supported by Contract NO1-HD-42856 from the National Institute for Child Health and Human Development, Center for Population Research. Dr. Thornton is affiliated with the Survey Research Center, Institute for Social Research, University of Michigan, Ann Arbor, MI 48106. Requests for reprints should be directed to him. 
POPULATION AND ENVIRONMENT

using longitudinal data collected from parents and their married children. In addition, the paper explores several mechanisms which could produce a relationship between parental characteristics and the fertility of the children.

\section{BACKGROUND}

\section{Parental Economic Status}

The first factor, parental economic status, holds an important position in socioeconomic models of fertility because of its relationship to consumption aspirations and desires. It has been hypothesized that children obtain their consumption aspirations and expectations from their parents (Easterlin, 1966, 1973a). Children are thought to become accustomed to the standard of living of their parents and as part of the socialization process to adopt it as their own. Thus, children raised in poor homes are expected to have fewer aspirations for material goods and to be satisfied with a lower standard of living than those raised in wealthy homes.

Consumption aspirations, in turn, are hypothesized to influence the childbearing of young adults (Easterlin, 1969, $1973 \mathrm{~b}$; Thornton, 1978). With any given combination of resources and prices the amount that can be spent for children and other things is determined, but the mixture of expenditures can vary. Therefore, since children require economic resources, it is plausible to assume that they compete with goods and services for family income. It is expected that the greater the aspirations for material goods, the more a family actually consumes and the fewer resources there are for children. Therefore, the theory predicts that the number of children varies inversely with the level of aspirations for material goods and positively with the amount of resources.

Changes in consumption aspirations coupled with swings in the economic achievement of young people have been hypothesized to explain the post-World War II fertility swing in the United States (Easterlin, 1962, 1966, and 1973a). Following World War II, young couples experienced particularly favorable financial circumstances because of their relatively small numbers and the expanding economy. Easterlin suggested that the baby boom was, in part, caused by these young couples translating their high incomes into increased fertility. 
In the early 1960 s, however, fertility began to decline while economic growth and prosperity continued. Easterlin found that, while economic conditions in general were still favorable, circumstances for young people were not keeping pace, accounting for some, but not all, of the reduction in fertility. In addition, Easterlin argued that young people in the 1960 s had greater aspirations for consumer goods than those of the 1940s and 1950 s and that these aspirations were competing with children for economic resources. By including consumption aspirations in the economic model, the framework could explain both the rise and subsequent decline in childbearing. During the 1940s and early 1950s, consumption aspirations were hypothesized to be at a fairly constant low level while income increased, resulting in relatively high fertility. During the 1960 s, the incomes of young people began leveling off while their aspirations increased greatly; the outcome was a decline in childbearing.

In testing the hypothesis, Easterlin was able to measure the income of cohorts of couṕles in a straightforward manner; however, it was not possible to measure consumption desires. But, since aspirations were assumed to develop in the parental home, Easterlin argued that parental economic status provided an adequate proxy for the children's consumption desires. The actual variable used in Easterlin's research was the ratio of the children's income to their consumption desires. The numerator, the income of the young adults, was expected to be positively related to fertility; the denominator, the parents' income, was hypothesized to be negatively related to fertility. The expectation, therefore, was that this ratio variable would be positively related to childbearing. When Easterlin compared time trends and movements in this measure with fertility, he found a correspondence. (See Easterlin, 1976; Lee, 1976; Bahr, Chadwick, \& Strauss, 1975; Chaudhury, 1977; De Fronzo, 1976; Freedman, 1976; MacDonald and Rindfuss, 1978; and Thornton, 1978 for further investigations of this hypothesis.)

\section{Parental Fertility}

The second factor to be considered in this paper is parental fertility. Several empirical studies have shown a relationship between the family sizes of successive generations, with children from large families being more likely to have many children themselves. Berent (1953) reported this association for a sam- 
ple of British couples, while a similar relationship has been observed in Barbados (George et al., 1976). Several studies of American fertility, including the Indianapolis Fertility Study (Kantner and Potter, 1954), the 1955 Growth of American Families Study (Duncan et al., 1965), the Princeton Study (Bumpass and Westoff, 1970), the 1965 National Fertility Study (Bumpass, 1975), the 1970 National Fertility Study (Stokes and Johnson, 1977), and a 1962 Current Population Survey (Duncan et al., 1965) support the proposition that there is an association between the number of children born to successive generations of adults. In addition, the positive relationship has been observed in a recent study of Pennsylvania women (Johnson and Stokes, 1976) and in a sample of young adults living in the South (Marshall and Cosby, 1977).

When this finding is placed within a broad theoretical framework, it is clear that there are several mechanisms which could produce a positive relationship between the family sizes of successive generations. One hypothesis explaining the relationship is that the orientation, desires, and norms of parents toward family size may be learned by their children during socialization. As a result, children from large families may desire and plan to have more children than others. The hypothesis that family size values and preferences are learned during socialization is supported by the fact that several studies have shown a positive relationship between the aspirations, preferences, expectations, and desires of young people concerning family size and the number of siblings they have (Gustavus, 1973 and 1975; Gustavus and Nam, 1970; Hendershot, 1969; Marshall and Cosby, 1977; McLaughlin, 1974; Patterson, 1972; Westoff and Potvin, 1967). In addition, a study of mothers and their adolescent children in Toronto revealed that the fertility ideals of the two generations were positively related (Simmons and Turner, 1976).

A second explanation of the positive association between first and second generation childbearing is that parents are a prime source of knowledge concerning birth control and its effective use. If so, children from homes where contraception is effectively used have more information and are better able to limit their own childbearing. Similarly, it is plausible to expect that the attitudes of parents toward birth control are passed on to their children through the socialization process. This explanation is consistent with the finding of Westoff and Potvin (1967) 
that the planned use of contraceptives by college women was negatively related to the family sizes of their parents.

A third explanation is that young adults may try to recreate role relationships existing in the family of orientation (Duncan et al., 1965), and these relationships depend to some extent upon the number of children in that family. The tendency to recapitulate those relationships would produce successive generations of families of similar sizes and could, therefore, operate independently of tastes and norms directly concerning family size and contraception. Johnson and Stokes (1976) investigated the relationship between family size in successive generations and concluded from their data that both "...norms and role relationships encountered in the family of orientation exert an influence on fertility behavior."

Finally, it is possible that natural fertility or fecundity itself is transmitted through genetic mechanisms. Couples with physical attributes conducive to high fertility may pass them on to their children. It is unlikely, however, that physiological mechanisms account for the entire relationship, since the positive association between fertility in successive generations has been observed in studies limited to fecund women (Duncan et al., 1965).

\section{DATA}

The Panel Study of Income Dynamics (Duncan and Morgan, 1976) provided a unique opportunity to investigate the influence of parental attributes and behavior on children, since it collected longitudinal information from both parents and their adult children. That study, which is still continuing, has interviewed a nationally representative cross-section of family heads annually since 1968. In addition, any member of a sample family who left his or her original family was included in the study, and the head of the new family unit was interviewed that year and all years thereafter. In every year, extensive information was collected concerning the economic organization and position of both the first and second generation families. The collected information included income of the husband, wife, and family as well as data concerning house value and assets. Every year, information was collected about children in the family, and, in 1972, a question was asked about expected family size.

Several indicators of fertility were used in the study. The first two, cumulative childbearing through 1972 and 1974, were used because they are behavioral indicators of fertility. Since all the second genera- 
tion couples married after the start of the panel study in 1968, cumulative fertility through 1972 and 1974 indicates childbearing during the first few years of marriage. Therefore, these measures reflect decisions about fertility timing as well as decisions about family size. For the analyses of cumulative fertility through 1972 and 1974, the samples of couples were limited to those married by the 1971 and 1973 interviews, respectively. Two other fertility variables, total expected family size and the number of children expected in addition to those already born, were based on the 1972 questions asking couples whether or not they expected to have any more children and, if so, how many they expected altogether. A final variable, the ideal family size of the second generation husband, was obtained in 1971 with the analysis of this variable limited to couples married by 1971 .

Extensive information concerning the parents and the parental homes of either the husband or wife in each family was obtained from the parents themselves. As a result, several measures of the economic status and fertility preferences of the parents were available. The measures from the first generation families used in this paper are outlined below:

1. Parental family head's ideal family size-from a standard question about the ideal size of the average American family.

2. Parental family head's income-the income of the father if present in the home; otherwise, the income of the mother.

3. Father's and mother's income-the income of both parents together.

4. Parental family income-the income of all earners in the parental family.

5. Parental welfare ratio-the ratio of family income to family needs.

6. Parental house value-the reported value of the house if owned; if rented, the value was estimated at ten times the annual rent.

7. Parental house value per person-parental house value divided by the number of persons in the family unit.

The indicators of parental economic status were obtained during each year of the study. To estimate an overall measure for each household, the average for the years the son or daughter was still in the parental home was obtained, taking into account inflation.

Three other parental measures were used in the analysis: the number of siblings of the husband; the husband's report of his father's educational attainment; and the husband's evaluation of the financial status of his parents, which was ascertained from the question, "Were your parents poor when you were growing up, pretty well-off, or what?" Responses concerning parental economic status were scored one for "poor," three for "average," or "it varied," and five for "pretty well-off." 
Unfortunately, the survey did not contain measures of fecundity, birth control, attitudes, or family role relationships in the parental family, so their influence could not be explored.

Hypotheses about the influence of first generation economic status and second generation consumption aspirations on second generation childbearing indicate that the explanatory variables should be considered together with the income of the second generation. Therefore, the second generation husband's income during the years prior to the 1972 and 1974 interviews were considered with the expectation that it would be positively related to fertility (based on the usual assumption that more income allows more resources for the bearing and rearing of children). In addition, several ratio variables, similar to the one created by Easterlin $(1966 ; 1973 a)$ were used to indicate the ratio o the husbands' income to the various indicators of the parental living levels. Given the hypothesis that the numerator of these ratio variables would be related positively and the denominator related negatively to the fertility variables, it was expected that the relationship between the ratio variables and fertility would be positive.

Not all couples were included in the analysis. Excluded were those for whom the present marriage was not the first, those who had experienced a marital disruption during the study period, and those with more than one child at the first interview following marriage. Also excluded were couples in which the husbands were not in the labor force. These exclusions operated to make the sample more homogenous.

Since a substantial number of the parental homes contained only one parent, it seemed possible that the analysis could be influenced by this factor (Hoffman, 1977; Ross and Sawhill, 1975); thus, preliminary analysis used data only for children from two-parent homes. The results obtained for this group, however, did not differ significantly from those for the whole sample and, therefore, the analysis reported here included children from both one and two-parent families.

\section{ANALYSIS}

\section{Parental Standard of Living}

In Table 1 are shown the zero order correlations between four of the fertility variables and the measures of financial status. Included in the bottom panel of the table are zero order correlations between the fertility measures and variables which were used in the multivariate analysis. The correlations between the indicators of parental financial status and the number of children already born were almost all negative. The correlations 
MEANS, STANDARD DEVIATIONS, AND ZERO ORDER CORREIATIONS OF CHILDREN IN THE FAMTLY IN 1972 AND 1974 , AND TOTAL EXPECTED AND ADDITIONAL EXPECTED CHILDREN IN 1972

\begin{tabular}{|c|c|c|c|c|}
\hline & $\begin{array}{c}\text { Children } \\
\text { Barn } \\
(1972)^{1} \\
\end{array}$ & $\begin{array}{l}\text { Ghildren } \\
\text { Born } 2 \\
(1974)^{2}\end{array}$ & $\begin{array}{c}\text { Total } \\
\text { Expected } \\
(1972)^{3} \\
\end{array}$ & $\begin{array}{c}\text { Additional } \\
\text { Expected } \\
(1972)^{3}\end{array}$ \\
\hline $\begin{array}{l}\text { Number of couples } \\
\text { Mean } \\
\text { Standard deviation }\end{array}$ & $\begin{array}{l}293 \\
.73 \\
.70\end{array}$ & $\begin{array}{l}566 \\
.82 \\
.76\end{array}$ & $\begin{array}{r}454 \\
2.38 \\
.98\end{array}$ & $\begin{array}{r}454 \\
1.79 \\
1.23\end{array}$ \\
\hline \multicolumn{5}{|l|}{ Correlation with: } \\
\hline $\begin{array}{l}\text { Parental head's Income } \\
\text { Father's and mother's income } \\
\text { Parental family income } \\
\text { Parental welfare ratio } \\
\text { Farental house value } \\
\text { Parental house value per person } \\
\text { Father's education } \\
\text { Parental financial status (reported by son) }\end{array}$ & $\begin{array}{l}-.052 \\
-.117 * \\
-.061 \\
-.135 * \\
.024 \\
-.066 \\
-.091 \\
-.055\end{array}$ & $\begin{array}{l}-.144 * \\
-.155 * \\
-.114 * \\
-.123 * \\
-.054 \\
-.063 \\
-.115 * \\
-.108 *\end{array}$ & $\begin{array}{r}-.026 \\
-.022 \\
.005 \\
-.041 \\
.032 \\
-.022 \\
.030 \\
-.005\end{array}$ & $\begin{array}{r}.012 \\
.024 \\
.015 \\
-.005 \\
-.005 \\
-.009 \\
.031 \\
.001\end{array}$ \\
\hline $\begin{array}{l}\text { Husband 's Income }^{4} \\
\text { Husband's income } \div \text { parental head's income }{ }^{4} \\
\text { Husband's income } \div \text { father's and mother's income }{ }^{4} \\
\text { Husband's income } \div \text { parental family incone }{ }^{4} \\
\text { Husband's income } \div \text { parental welfare rat10 }\end{array}$ & $\begin{array}{l}.123^{*} \\
.092 \\
.119 * \\
.111 \\
.169 *\end{array}$ & $\begin{array}{r}-.004 \\
.102 * \\
.123 * \\
.082 \\
.113^{\star}\end{array}$ & $\begin{array}{r}.002 \\
.097 \\
.087 \\
-.018 \\
.081\end{array}$ & $\begin{array}{l}-.082 \\
.011 \\
-.008 \\
-.103 * \\
-.031\end{array}$ \\
\hline $\begin{array}{l}\text { Husband's education } \\
\text { Wife's education } \\
\text { Year married } \\
\text { Race (white }=0 \text {, other }=1 \text { ) } \\
\text { Religton (Catholic }=1 \text {, other }=0 \text { ) }\end{array}$ & $\begin{array}{r}-.215 * \\
-.239 * \\
-.291 * \\
.142 * \\
.156 *\end{array}$ & $\begin{array}{l}-.226 * \\
-.159 * \\
-.432 * \\
.109 * \\
-.062\end{array}$ & $\begin{array}{l}.098 \\
.056 \\
.108 * \\
.038 \\
.165\end{array}$ & $\begin{array}{c}.190 * \\
.163 \star \\
.301 \star \\
-.026 \\
.106 *\end{array}$ \\
\hline
\end{tabular}

*Correlation is larger than two times its atandard error, computed using the assurptions of simple random sampling and ignoring the design effects produced from the complex sample design used.

${ }^{1}$ Includes couples married by 1971 interview.

2 Includes couples narried by 1973 interview.

3 Includes couples married by 1972 interview.

${ }^{4}$ For the 1972 analysis hushand's income refers to 1971 Income. Por 1974 analys1a, 1973 1ncome 18 used.

tended to be larger in 1974 than in 1972 and, with almost 600 cases, most were statistically significant. The correlations of the independent variables with total expected and additional expected fertility were quite inconsistent in direction, and none were large enough to discount the possibility that they were produced by sampling variability.

The correlation between fertility and the husband's income depended on the year and measure examined. Parity and income in 1972 were positively and significantly related. There was, however, virtually no correlation between husband's income and parity in 1974, nor between income and total children expected. The correlation between income and additional children expected was negative. Note that the variables indicating the husband's income relative to the various measures of parental status were positively related to 1972 and 1974 parity 
and, with one exception, to total expected fertility, but they were not positively related to additional children.

A multivariate approach permits the influence of other important variables to be controlled, and in this research two different sets of multivariate controls were used. The first, referred to as Model 1, controlled the year the couple married (scored one for the first year of the panel, through five for the fifth year), race, and religion. The last two variables were operationalized as dichotomies: for race, the values were 0 for whites and 1 for nonwhites; for religion, Catholics were coded 1 , while all others were coded 0 .

Model 2 controls were designed to ascertain the extent to which the inclusion of parental economic status into a fertility model increases understanding of the mechanisms involved. Research has shown a negative relationship, albeit decreasing with time, between a couple's level of education and childbearing (Kiser, Grabill, \& Kantner, 1968; Ryder and Westoff, 1971; and Blau and Duncan, 1967). In addition, stratification research has shown a positive correlation between the socioeconomic statuses of successive generations (Blau and Duncan, 1967). These two relationships alone would produce a negative correlation between first generation status and second generation fertility.

The examination of whether or not parental status had a direct effect upon second generation childbearing, net of the influence of second generation status, was accomplished by including the education of both husband and wife of the second generation in the analysis. In addition, to take into account the effect of the other background factors, all controls from Model 1 were also included in Model 2. A substantial relationship between parental status and children's fertility with Model 2 controls would indicate that the inclusion of parental status did improve the usual one generation model.

The multivariate analysis was conducted using ordinary least squares regression. The financial indicators used in the multivariate analysis were limited to husband's income, parental head's income, parental welfare ratio, and the ratio of husband's income to the two parental variables. Four different equations were estimated for both the Model 1 and Model 2 analyses. The first two equations contained husband's income and one of the parental variables while the third and fourth equations contained the ratio of husband's income to one of the 
parental variables. The standardized regression coefficients for the financial variables from both the Model 1 and Model 2 analyses are listed in Table 2.

Husband's income was positively related to 1972 parity using both Model 1 and Model 2 controls (Equations 1 and 2 of Table 2). However, the relationship was not large enough to be statistically significant in the modest-sized sample of couples married by 1971 . Also note that in model 1 both measures of parental status were negatively related to fertility, with the welfare ratio variable having enough impact to be statistically significant. However, when Model 2 was used, the negative coefficients were reduced substantially, with the effect of the parental head's income reversing its sign. Similarly, when the ratio variables were entered into the model their direct influence was very minor (and even negative in one case).

The results for 1974 parity, presented in the second panel of Table 2, were quite different from those for 1972 parity. The husband's 1973 income did not have the expected positive influence on the number of children born. Rather, in Model 1, its impact was negative and large enough to be statistically significant. With the addition of education into Model 2, the magnitude of the coefficient was reduced, but it remained negative. It should be observed that the reverse in sign from 1972 to 1974 was not the result of changing the sample; when the 1972 sample was analyzed in 1974, the same negative coefficients were observed (the results are not shown here).

While the husband's income did not show a positive effect in 1974, the hypothesized negative influence of parental status did exist. In Model 1 both indicators of parental finances had moderately large negative coefficients, and the coefficients persisted but with reduced magnitude in Model 2 . These results imply that parental status had a large overall impact on childbearing but that much of the influence was transmitted through the education of the offspring. In fact, the effect remaining in Model 2 was not large enough to be statistically significant.

The analysis shown in Equations 3 and 4 of the two models indicates that the ratio variables were only moderately related to 1974 parity, and the direction of the relationship depended upon the model. Furthermore, neither variable contributed anything to the explanatory power of the models. These results were undoubtedly due to both the numerator and denominator of the variables being negatively correlated to number of 
TABLE 2

MULTIPLE REGRESSION ANALYSIS OF THB RELATIONSHIP BETWBEN ECONOMIC MEASURES AND 1972 PARITY, 1974 PARITY, 1972 TOTAL EXPECTED FAMILY SIZE, AND ADDITIONAL CBILDREN EXPECTED IN 1972

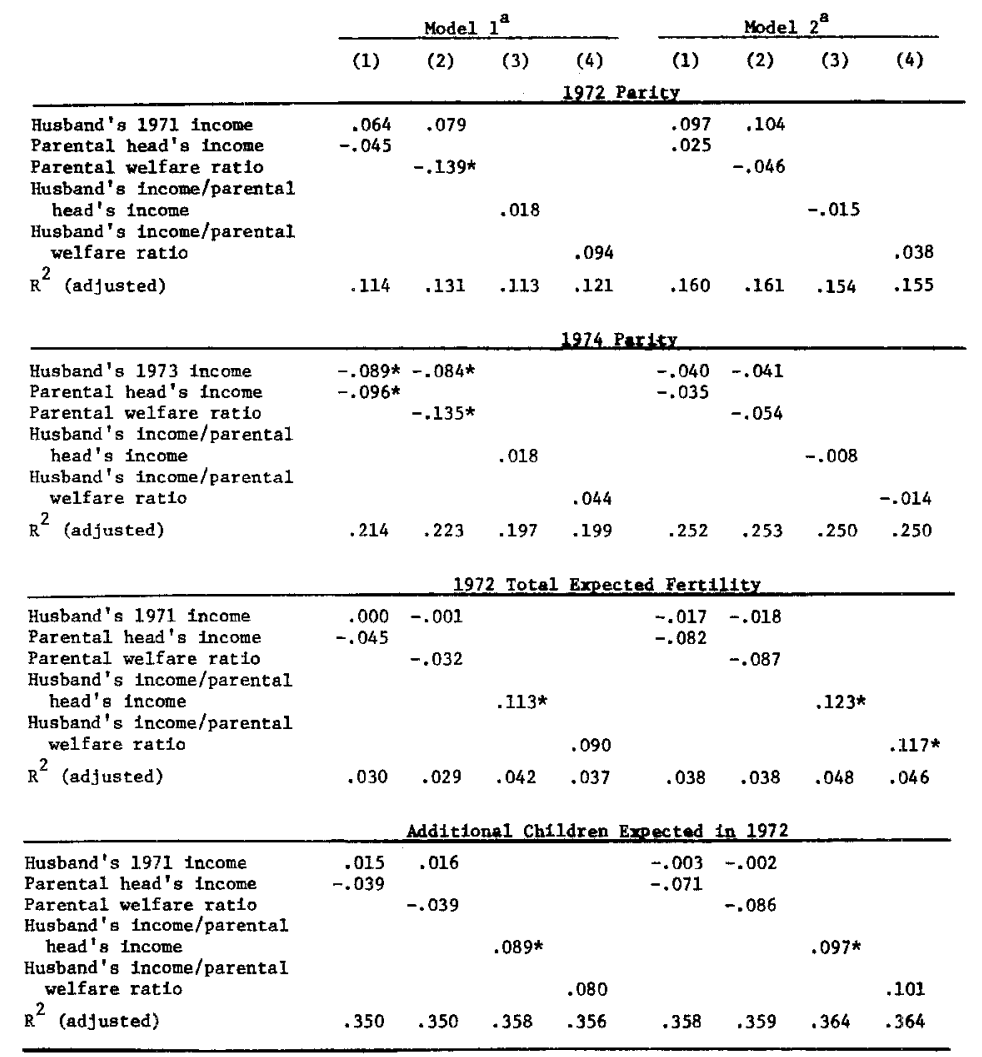

* Coefficlent is at least two times 1ts standard error (computed using the assumptons of aimple random sampling and tgnoring the design effects produced from the complex sample destgn used).

arodel 1 controlled year marrled, religion, and race, while Model 2 controlled these three variables plus husband's and wife's education. In addition, for both Models 1 and 2 of the analys1s of additional children expected in 1972, current parity was controlled. The adfusted $\mathrm{R}^{2}$ values for the equations containfing only the control varlables were .115, .199, .032 , and .352 respectively for Model 1 and $.157, .252, .036$, and .356 respectively for Model 2. Al1 coefficients are standardized regression coefficients.

children. By using the ratio form, the two effects cancelled each other.

The analysis of total expected family size is reported in the third panel of Table 2. These data are not consistent with the hypothesis that greater income increases childbearing. In both 
models, the husband's income failed to show a positive influence. However, parental status did show the hypothesized effect in both models. Indeed, the parental coefficients were larger (but still not twice their standard errors) in Model 2 than in Model 1 . This result indicates that the direct or net influence of parental status on expected childbearing was larger than the gross or zero order influence. Also, as hypothesized, the ratio variables were positively associated with expected fertility. In fact, these variables added more to predictive power (increase in $\mathrm{R}^{2}$ ) than did their components when entered individually.

A review of the data in the fourth panel of Table 2 indicates that the results for additional children expected were very similar to those for total expected family size. The husband's income was not related to the dependent variable, and the impact of parental status was negative. As before, the estimated direct influence of parental income was larger in Model 2 than in Model 1. The coefficient for the ratio of the husband's income to the parental standard of living was also positive, as hypothesized. The similarity of the results in Panels 3 and 4 is probably due to the fact that the couples studied were still very much newly-weds. For them, additional expected childbearing was a much larger component of the total number of children expected than was the number already born.

\section{Parental Family Size and Ideal Family Size}

The analysis of the influence of the first generation family on second generation fertility was conducted by first determining the zero order relationships between first and second generation fertility and then, as in the previous section, controls were added in a stepwise fashion. Model 1 controls included the income of the parental head and the year married, religion, and race of the second generation husband. In Model 2, the educational attainment of the second generation husband and wife were taken into account along with the Model 1 controls. The standardized regression coefficients for the number of siblings of the husband are shown in equation 1 of Models 1 and 2 , while the coefficients for the ideal family size of the head of the parental family are shown in equation 2 of the two models (Table 3).

Both measures of parental fertiity were positively associ- 
TABLE 3

THE RELATIONSHIP BETWEEN PARENTAL ACTJAL AND IDEAL FAMILY SIZE AND SECOND GENERATION IDEAL FAMILY SIZE, TOTAL CHILDREN EXPECTED, 1972 PARITY, AND 1974 PARITY

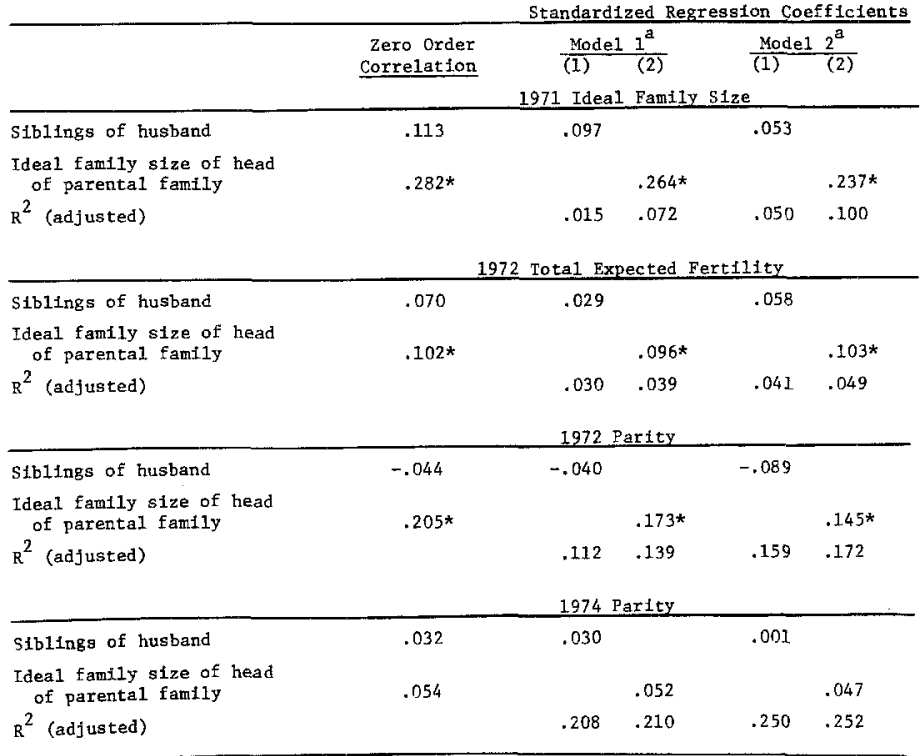

* of simple random sampling and ignoring the design effects produced from the complex sample design used).

a The coefficients shown were produced by separately entering siblings of husband and ideal family size of head of parental family into equations containing the Model 1 ideadel 2 controls. Model 1 controls included the income of the head of the and Wed the year married, race, and religion of the second generat parental family anc 2 controls included husband's and wife's education in addtion to those of Model 1.

ated with the ideal number of children reported by the second generation husband (panel 1 of Table 3 ). The zero order correlation of .282 for parental ideal family size was both substantively important and statistically significant. The introduction of controls, however, reduced the magnitude of the observed relationships for both independent variables. With the Model 2 controls the coefficient for actual parental fertility was reduced to .053 while that of parental ideal family size was reduced to .237 .

The analysis of the total number of children expected by the husband of the second generation family is reported in the second panel of Table 3. As expected, there was a positive correlation between total expected children and the measures 
of parental fertility. However, the coefficients were not as large as the ones observed in the first panel. Again, the ideal family size of parents was a better predictor of the fertility of the second generation than was the actual family size of the parents. Both the zero order correlation coefficient and standardized regression coefficients for the ideal measure were substantially larger than those for the number of siblings.

It should be noted that the introduction of the Model 1 controls reduced the observed relationships somewhat. With the introduction of education, however, the coefficients increased. This result is due to the unexpected positive relationship between education and expectations of fertility. Thus, for total fertility expectations, the overall influence of the parental variables is not mediated through the children's own social status.

The data in Panels 3 and 4 suggest that there was no relationship between parental family size and actual parity achieved by 1972 and 1974. In both 1972 and 1974, the coefficients were not statistically significant. The ideal family size of the first generation, however, was related to parity in both years. In 1972 the relationship was substantial and large enough to exlude sampling error as the force producing it. Even with full controls, the standardized coefficient was .145. In the 1974 data, the coefficients were substantially smaller and, even with a larger sample, not statistically significant. Note that the difference between the two years was only partially the result of adding couples between the two time periods. When the 1974 analysis was limited to couples studied in 1972, the coefficeints were still much smaller than in 1972 (results not shown).

\section{DISCUSSION}

Several points should be made about the observed results. First, family size in the first generation was positively related to expected and ideal family size in the second. While the relationships between the size of the parental family and fertility preferences and expectations were not large enough to be statistically significant, they were in the predicted direction. However, there did not appear to be a positive relationship between actual parental family size and parity achieved during the first few years of second generation marriages. This result 
may have been due to the fact that the measures of current parity reflected spacing decisions more than family size decisions. In addition, it should be noted that the effect of parental family size on ideals and expectations was smaller than the effects reported by Duncan et al. (1965) concerning the influence of parental fertility on second generation family size. These data, therefore, do not indicate a substantial impact of actual first generation family size on second generation childbearing.

Second, the ideal family size of parents related positively to the second generation fertility variables examined. In addition, in three of the four analyses, the effect was large enough to be statistically significant. Also, the influence of the variable was fairly substantial, perhaps not large in terms of explained variance, but in terms of practical and demographic significance. The unstandardized regression coefficients with full controls indicate that a one-child increase in parental preferences enlarged second generation ideal family size by over .15 , total expected fertility by .08 , achieved parity in 1972 by .08 , and 1974 parity by .03 (data not shown in Tables).

It it important to observe that parental family size preferences were more closely related to second generation fertility than was actual first generation family size. Apparently, values and attitudes concerning family size play a more important role than does the number of siblings in the family of orientation. This result is especially important in light of the way the variables were measured. As second generation information was obtained from the husband, second generation ideals and expectations were those of the husband rather than those of the wife. The measure of first generation family size was also obtained by asking the husband about the number of siblings he had. On the other hand, the ideal family size of the first generation could have been reported by either the wife's parents or the husband's parents, depending on who had been in the original panel. The analysis related the husband's ideal family size and expectations to his parents' family size and also to the ideal family size of either his or his wife's parents. While the procedure should provide an unbiased estimate of the correlation between parental family size and second generation measures, the relationship between the ideal family size of the parents and the variables measured for the children are probably biased downward. 
Third, if only the number of children born by 1972 had been analyzed, we would have found evidence consistent with the hypothesized positive effect of second generation income. Current parity in 1972 was positively and significantly correlated to 1971 income (Table 1). With controls, the relationship remained positive but was not large enough to be statistically significant. Income, however, failed to have a substantial positive influence on any of the other three fertility variables examined. Depending on the model and measure employed, the husband's income had either a very small positive effect or a negative influence. Thus, the results, taken as a whole, do not support the hypothesis that income increases childbearing.

Fourth, concerning parental economic status, it was found that virtually all indicators were negatively correlated with children born by 1972 and 1974 (Table 1). When controls for other variables were employed and the influence of the variable was examined within the context of Model 1 , the negative association persisted and remained large. However, when the two intervening variables of the husband's and the wife's education were entered in the equation (Model 2), the coefficients indicating the direct influence of parental status on children born were small and not statistically significant, suggesting that much of the total influence was transmitted through education.

The correlation of parental status with fertility plans was less consistent and striking. The overall influence seemed small and was statistically insignificant but, when Model 2 controls were used, the magnitude of the direct effect was larger. The increase of the coefficients with Model 2 was due to the positive correlation of education to childbearing plans. However, in none of the Model 2 analyses were the coefficients for parental status twice as large as their standard errors.

The ratio of the husband's income to parental financial status was positively correlated with parity in 1972 and 1974. The relationships persisted at a reduced level using Model 1 controls, but they either disappeared or were negative in Model 2. When fertility plans were studied, however, the influence of the ratio variables was positive and fairly substantial in both Model 1 and Model 2.

While the results of this analysis are not completely consistent, they generally support the hypothesis that high parental status decreases childbearing. This microlevel result gives 
credence to the Easterlin $(1966 ; 1973 a)$ hypothesis that during the 1960 s young couples were coming from affluent homes and, as a result, had lower fertility. However, it is difficult to say why the couples from affluent homes had fewer children. The results of the research reported here indicate that much of the overall impact of parental status on actual second generation childbearing was transmitted through the education of the second generation. That is, children from high status families had few children largely because they themselves were high status. There was little effect of parental economic status that could not be accounted for by the children's own status.

This brings us to the basic question: How is parental economic status transmitted into second generation fertility? Easterlin $(1966 ; 1973 a)$ indicated that the mechanism was consumption standards. He argued that children internalize the parental living levels as their own standard of consumption. Therefore, children raised in wealthy homes would have greater aspirations for material goods. Since Easterlin's model hypothesizes that high aspiration levels decrease child bearing, it follows that high parental living levels would decrease second generation fertility.

Unfortunately, neither Easterlin's data nor the data used in this research permitted the influence of consumption aspirations to be tested directly. We have shown, however, that, if education is not a proxy for aspirations or at least fairly closely related to it, the influence of aspirations on actual fertility cannot be very large. The supporting evidence is that, when the effect of education was controlled, the net or direct effect of parental status was small and not statistically significant; there was little effect operating independently of education. However, it is quite possible that education is, indeed, a reasonable proxy for aspiration. If so, our results are consistent with the notion that the influence of parents operates through consumption standards.

All of this, of course, leaves us with the problem described by Schultz (1973): We do not know exactly what education specifies. As he indicates, education affects many different things, and a review of the literature would indicate that it has been used in empirical research as a proxy for several concepts. This ambiguity suggests the need to move away from using the global concept of education as a proxy for some particular theoretical concept and to try to measure the theoretical notion 
itself. This is necessary because,as Ryder (1973) points out, "... the data are blind to the concepts of the theorist, and wife's education means whatever it means."

In explaining the relationship between parental economic status (and also parental family size and family size preferences) and the fertility of adult children, it is important to recognize that there are several mechanisms which could produce the association. Several sociological, economic, psychological and demographic constructs have been identified as having a possible impact on fertility levels (Becker, 1960; Davis and Blake, 1956; Easterlin, 1969, 1973; Goldberg, 1975; Hawthorne, 1970; Hoffman and Hoffman, 1973; Leibenstein, 1957; Journal of Political Economy, 1973, 1974; Scanzoni, 197.5; Turchi, 1975), and it is possible that parental variables could influence second generation fertility through any of these characteristics. Figure 1 lists several variables identified by Easterlin (1969, 1973b; also see Thornton, 1978) as being important determinants of fertility.

Figure 1 also expands the usual one-generation framework to include parental economic status and family size and could be expanded even further to include other aspects of the parental family. The relationship between first generation variables and children's fertility is neither simple nor straightforward. The hypothesis that parental income influences con-

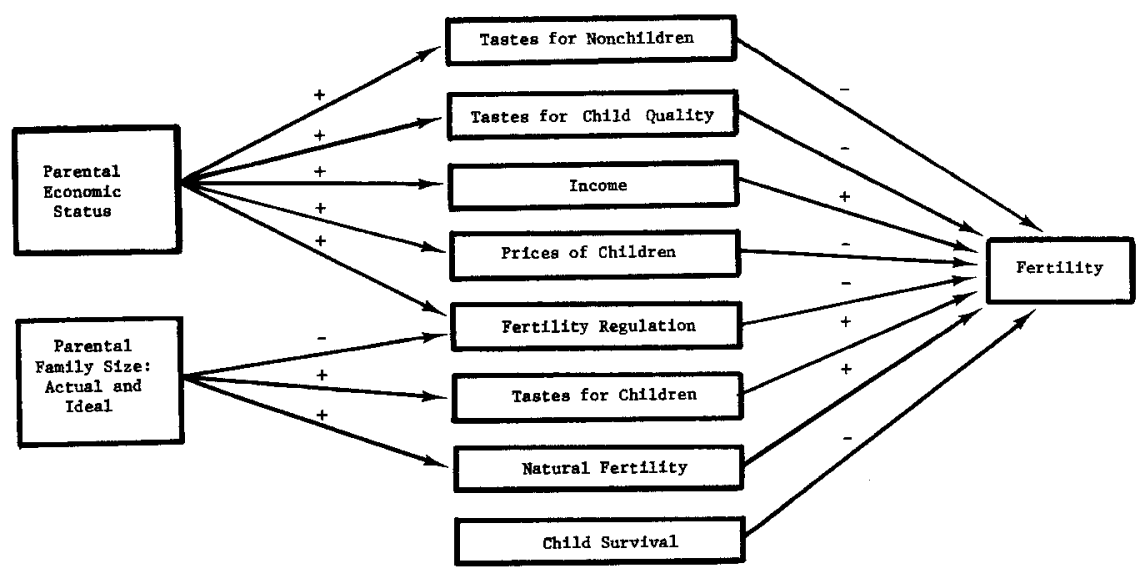

Figure 1. General Framework of Fertility including Parental Variables (hypothesized signs of effects are shown) 
sumption aspirations is represented by the positive arrow between parental status and tastes for nonchildren (which includes both material and nonmaterial things that could compete with children for money and time resources). However, if parental income affects consumption aspirations, it could also influence standards about inputs necessary to rear children (child quality) as well as increasing knowledge of, and access to, means of regulating childbearing, and these factors should operate to decrease second generation childbearing. We also know that parental status enhances the education and occupation of children (Blau and Duncan, 1967), and economic models suggest that increased human capital raises the price of child care since most of it is done by parents; this would also decrease family size. At the same time, education and occupation increase income, which is hypothesized to raise fertility. Note that while child survival, natural fertility, and desires for children are shown to influence childbearing in Figure 1, the influence of the parent's standard of living on these variables is assumed to be zero, but even these assumptions may be overly simplistic.

The mechanisms hypothesized to produce the overall positive relationship between family sizes in two generations are also shown in Figure 1. Parental family size is hypothesized to be related to desires for children, natural fertility or fecundity, and the use of birth control in the second generation. All of these mechanisms could be producing the observed positive association between family sizes. Note that the figure does not include direct links between parental family size and tastes for nonchildren, child quality standards, income, prices of children, and child survival. Again, these exclusions are only hypotheses; additional research might establish direct links. Figure 1 does not include one possible link between first and second generation family sizes: the hypothesized desire of children to imitate role relations existing in the parental home. This exclusion is motivated not by a hypothesis that the mechanism is not important, but rather by the fact that the mechanism is complex and difficult to diagram in a simple figure.

If measures of all the variables in the theoretical system were available, it would be possible to estimate the influence of parental attributes on the second generation variables. In addition, one could estimate the mechanisms through which parental variables operate to influence childbearing. That is, 
with measures of all variables, it would be possible to determine which intervening variable was transmitting the influence of parental status. It is crucial to note that, without measuring the intervening variables, it is possible to estimate only the overall influence of parental background, but it is not possible to estimate the mechanisms. Thus, for example, in the absence of measures of the intervening variables, any relationship observed between parental income and second generation family size would have to be considered as the sum of the influences operating through all of the intervening variables. Without making assumptions that many of the influences shown are zero (which seems rather unlikely), it would not be possible to state that the relationship was the result of only one mechanism. Although a relationship may exist between parental economic status and fertility, it would seem hasty to conclude the effect was only (or even in part) transmitted through aspirations for consumption goods. While it is certainly possible that some or even much of the influence is so transmitted, the model is too complex to discover this fact without measures of the intervening variables themselves. By measuring the variables specified and then estimating their effects, it would be possible to better understand the mechanism involved.

In summary, the data reported in this paper are consistent with the hypothesis that conditions existing in the family of orientation are related to childbearing in the family of procreation. Both parental fertility and parental economic status were found to be related to second generation fertility. However, while there does appear to be a correlation between several characteristics of first generation families and second generation fertility, the transmittal of behavior and attitudes is certainly less than perfect, as indicated by the fact that many of the observed relationships were only of small or moderate magnitude. This indicates that there are many other factors determining the behavior and attitudes of young people besides those in the parental family. In addition, our understanding of the mechanisms producing the correlations between parental characteristics and second generation fertility is very limited, which underscores the importance of additional research focusing directly on the hypothesized mechanisms. 
ARLAND THORNTON

\section{REFERENCES}

Becker, G.S. An economic analysis of fertility. In National Bureau of Economic Research, Demographic and Economic Changes in Developing Countries. Princeton: Princeton University Press, 1960.

Berent, J. Relationship between family size of two successive generations. Millbank Memorial Fund Quarterly, 1953, 31 39-50.

Blau, P.M. and Duncan, O.D. The American Occupational Structure. New York: John Wiley and Sons, Inc., 1967.

Bahr, S.B. Chadwick, A. and Strauss, J.H. The effect of relative economic status on fertility. Journal of Marriage and the Family, 1975, 37, 335-343.

Bumpass, L.L. Data relevant to socialization in the U.S. National Fertility surveys. Papers of the East-West Population Institute, 1975, 36.

Bumpass, L.L. and Westoff, C.F. The Later Vears of Childbearing. Princeton: Princeton University Press, 1970.

Chaudhury, R.H. Relative income and fertility. Demography, 1977, 14, 179-196.

Davis, K., and Blake, J. Social structure and fertility: an analytic framework. Economic Development and Cultural Change, 1956, 211-235.

De Fronzo, J. Cross sectional areal analyses of factors affecting marital fertility: actual versus relative income. Journal of Marriage and the Family, 1976, 38, 669-676.

Duncan, G.J., and Morgan, J.N. Five Thousand American Families-Patterns of Economic Progress, Vol. IV. Ann Arbor: Institute for Social Research, 1976.

Duncan, O.D. Freedman, R., Coble. J.M. and Slesinger, D.P. Marital fertility and the size of family or orientation. Demography, 1965, 2, 508-515.

Easterlin, R.A. The American baby boom in historical perspective. National Bureau of Economic Research Occasional Paper 79, 1962.

Easterlin, R.A. On the relation of economic factors to recent and projected fertility changes. Demography, 1966, 3, 131-153.

Easterlin, R.A. Towards a socioeconomic theory of fertility: a survey of recent research on economic factors in American fertility. In S.J. Behman, L. Corsa, Jr., and R. Freedman (eds.)., Fertility and Family Planning. Ann Arbor: The University of Michigan, 1969.

Easterlin, R.A. Relative economic status and the American fertility swing. In E. B. Sheldon (ed.), Family and Economic Behavior. Philadelphia: J.B. Lippincott Company, $1973 \mathrm{a}$.

Easterlin, R.A. The economics and sociology of fertility: A synthesis. Revised version of a paper prepared for the Seminar on Early Industrialization, Shifts in Fertility, and Changes in Family Structure Institute for Advanced Study, Princeton, New Jersey, June 18-July 9, 1972. Revised 1973b.

Easterlin, R.A. The conflict between aspirations and resources. Population and Development Review, 1976, 2, 417-426.

Freedman, D. Fertility, aspirations and resources: a symposium on the Easterlin hypothesis. Population and Development Review, 1976, 2, 411-416.

George, P.M., Ebanks, G.E., Nobbe, C.E. and Anwar, M. Fertility differences between the family of orientation and the family of procreation in Barbados. International Journal of Sociology of the Family, 1976, 6, 57-69.

Goldberg, D. Socioeconomic theory and differential fertility. Social Forces, 1958, 54, 84106.

Gustavus, S.O. The family size preferences of young people: a replication and follow-up study. Studies in Family Planning, 1973, 4, 335-342.

Gustavus, S.O. Fertility socialization research in the United Status: A progress report. Papers of the East-West Population Institute, 1975, 35.

Gustavus, S.O., and Nam, C.B. The formation and stability of ideal family size among 
POPULATION AND ENVIRONMENT

young people. Demography, 1970, 7, 43-51.

Hawthorne, G. The Sociology of Fertility. London: Collier-MacMillian, 1970.

Hendershot, GE. Family satisfaction, birth order, and fertility values. Journal of Marriage and the Family. 1969, 31, 27-33.

Hoffman, L.W. and Hoffman, M.L. The value of children to parents. In J.T. Fawcett (ed.), Psychological Perspectives on Population. New York: Basic Books, 1973.

Hoffman, S. Maritial instability and the economic status of women. Demography, 1977 , $14,67-76$.

Johnson, N.E. and Stokes, C.S. Family size in successive generations: the effects of birth order, intergenerational change in lifestyle, and familial satisfaction, Demography, $1976,13,175-187$.

Journal of Political Economy Supplement, March/April 1973, 81 (2).

Journal of Political Economy Supplement, March/April 1974, 82 (2).

Kantner, J.F. and Potter, R.G., Jr. Social and psychological factors affecting fertility. XXIV. The relationship of family size in two successive generations. Milbank Memorial Fund Quarterly, 1954, 32, 294-311.

Kiser, C.V., Grabill, W.H., and Campbell, A.A. Trends and Variations in Fertility in the United States. Cambridge: Harvard University Press, 1968.

Lee, R.D. Demographic forecasting and the Easterlin hypothesis. Population and Development Review, 1976, 2, 459-468.

Leibenstein, H. Economic Backwardness and Economic Growth. New York: Wiley; London: Chapman and Hall, 1957.

Marshall, K.D., and Cosby, A.R. Antecedent of early marital and fertility behavior. Youth and Society, 1977, 9, 191-212.

McDonald, M.M. and Rindfuss, R.R. Relative economic status and fertility: evidence from a cross-section. In J.L. Simon (ed.), Research in Population Economics. Greenwich: Johnson Associates, 1978.

McLaughlin, S. Expected family size and perceived status deprivation among high school senior women. Demography, 1974, 11, 57-75.

Paterson, N. Adolescent family size preferences. International Journal of Sociology of the Family, 1972, 2, 231-245.

Ross, H.L., and Sawhill, I.V. Time of Transition: The Growth of Families Headed by Women. Washington, D.C.: The Urban Institute, 1975.

Ryder, N.B. Comment on: a new approach to the economic theory of fertility behavior, by R.J. Willis. Journal of Political Economy, 1973, 81, 565-569.

Ryder, N.B. and Westoff, C.F. Reproduction in the United States: 1965. Princeton: Princeton University Press, 1971.

Scanzoni, J.H. Sex Roles, Life Styles and Childbearing Changing Patterns in Marriage and the Family. New York: The Free Press; London: Collier-Macmillian, 1975.

Schultz, T.W. The value of children: an economic perspective. Journal of Political Economy, 1973, 81, 502-513.

Simmins, A. B., and Turner, J.B. The socialization of sex roles and fertility ideals: a study of two generations in Toronto. Journal of Comparative Family Studies, 1976, 1, 255271.

Stokes, C.S., and Johnson, N.E. Birth order, size of family of orientation, and desired family size. Journal of Individual Psychology, 1977, 33, 42-46.

Thornton, A. The relationship between fertility and income, relative income, and subjective well-being. In J.L. Simon (ed.), Research in Population Economics, Greenwich: Johnson Associates, 1978.

Turchi, B.A. The Demand for Children: The Economics of Fertility in the United States. Cambridge: Ballinger, 1975.

Westoff, C.F. and Potvin, R.H. College Women and Fertility Values. Princeton: Princeton University Press, 1967. 